\title{
Acute Kidney Injury Model Induced by Cisplatin in Adult Zebrafish
}

\author{
Camila Morales Fénero ${ }^{*}, 1$, Barbara Nunes Padovani ${ }^{*}, 1$, Mariana Abrantes do Amaral ${ }^{*}, 1,2$, Guilherme José Bottura de \\ Barros $^{1}$, Izabella Karina Xavier de Oliveira ${ }^{1}$, Meire loshie Hiyane ${ }^{1}$, Niels Olsen Saraiva Camâra ${ }^{1,2}$ \\ ${ }^{1}$ Department of Immunology, University of São Paulo ${ }^{2}$ Department of Medicine, Nephrology Division, Federal University of São Paulo \\ *These authors contributed equally
}

\section{Corresponding Author}

Camila Morales Fénero

ci.moralesfe@gmail.com

\section{Citation}

Morales Fénero, C., Padovani, B.N., do Amaral, M.A., de Barros, G.J.B., de Oliveira, I.K.X., Hiyane, M.I., Camâra, N.O.S. Acute Kidney Injury Model Induced by Cisplatin in Adult Zebrafish. J. Vis. Exp. (171), e61575, doi:10.3791/61575 (2021).

\section{Date Published}

May 15, 2021

DOI

$10.3791 / 61575$

URL

jove.com/video/61575

\section{Abstract}

Cisplatin is commonly used as chemotherapy. Although it has positive effects in cancer-treated individuals, cisplatin can easily accumulate in the kidney due to its low molecular weight. Such accumulation causes the death of tubular cells and can induce the development of Acute Kidney Injury (AKI), which is characterized by a quick decrease in kidney function, tissue damage, and immune cells infiltration. If administered in specific doses cisplatin can be a useful tool as an AKI inducer in animal models. The zebrafish has appeared as an interesting model to study renal function, kidney regeneration, and injury, as renal structures conserve functional similarities with mammals. Adult zebrafish injected with cisplatin shows decreased survival, kidney cell death, and increased inflammation markers after $24 \mathrm{~h}$ post-injection (hpi). In this model, immune cells infiltration and cell death can be assessed by flow cytometry and TUNEL assay. This protocol describes the procedures to induce AKI in adult zebrafish by intraperitoneal cisplatin injection and subsequently demonstrates how to collect the renal tissue for flow cytometry processing and cell death TUNEL assay. These techniques will be useful to understand the effects of cisplatin as a nephrotoxic agent and will contribute to the expansion of AKI models in adult zebrafish. This model can also be used to study kidney regeneration, in the search for compounds that treat or prevent kidney damage and to study inflammation in AKI. Moreover, the methods used in this protocol will improve the characterization of tissue damage and inflammation, which are therapeutic targets in kidney-associated comorbidities.

\section{Introduction}

The kidneys are responsible for several important physiological functions that maintain homeostasis, such as blood filtration, removal of excess residues, and regulation of ion concentrations ${ }^{1}$. Damage of renal tissue can lead to a heterogeneous condition called Acute Kidney Injury (AKI), which clinically is described as a rapid decrease in renal 
function caused by destruction and death of tubular epithelial cells, endothelial cell injury, and leukocyte infiltration 2,3 . AKI is a condition projected to happen in $8-16 \%$ of hospital admissions ${ }^{4}$, with a high mortality rate that ranges from 20 to $50 \%$ in the intensive care unit $(\mathrm{ICU})^{5}$. This ailment is associated with increased hospital stay and considerable use of financial resources ${ }^{5}$. Etiologic factors include dehydration, shock, infections, sepsis, cardiovascular disease, and nephrotoxic drugs ${ }^{6}$. Nephrotoxicity is defined as a renal injury induced by drugs, causing effects as AKI, tubulopathies, and glomerulopathies ${ }^{7}$. Nephrotoxicity affects two-thirds of ICU patients, as approximately $20 \%$ of the drugs prescribed in ICU are considered nephrotoxic ${ }^{8,9}$, this includes nonsteroidal anti-inflammatory drugs (NSAIDs), antibiotics such as vancomycin and aminoglycosides, and chemotherapeutic agents like methotrexate and cisplatin ${ }^{7}$. Cisplatin is one of the most potent and common chemotherapy drugs, used in the treatment of solid tumors, such as head and neck, testicular, ovarian, and bladder ${ }^{10}$. In the kidney, cisplatin is internalized in the proximal convoluted tube (PCT) through the organic cationic transporter 2 (OCT-2) and in high concentrations binds to the DNA triggering cell death pathways $7,10,11,12$. The accumulation of this drug in the kidney contributes to nephrotoxicity with death and inflammation ${ }^{13}$. This detrimental side effect affects enormously the life and prognosis of one-third of cancer patients undergoing cisplatin treatment, so is imperative the research of new therapies that can lower the nephrotoxicity without losing the killing effect on cancer cells ${ }^{10}$.

Because of this nephrotoxic effect, cisplatin is commonly used as an inductor of $\mathrm{AKI}$ in experimental animal models, as described forward. In rodents, the first AKI model induced by cisplatin was reported in $1971^{14}$ but at present, many different protocols have emerged using the dose-dependent and cumulative effects of cisplatin ${ }^{15}$. Thereby, depending on the dosage and number of applications, different grades of severity of kidney injury can be induced $16,17,18,19,20,21$. The most frequent method consists of an intraperitoneal (i.p.) injection of one dose of cisplatin followed by euthanasia in the following days. In this classic protocol, a single high nephrotoxic dose of cisplatin (10-13 mg/kg in mice and/or 3-8 $\mathrm{mg} / \mathrm{kg}$ in rats) induces severe histological changes, such as loss of brush border and cell debris inside the tubular lumen, a few days after cisplatin injection. The severity of histological changes is dose-dependent, and signs of regeneration are observed 7 days after cisplatin injection ${ }^{16,17}$.

Although rodent models are well established, we decided to take advantage of the characteristics of another vertebrate, focusing our studies on the zebrafish (Danio rerio). This fish has been extensively used for modeling human diseases, because of its small size, external fertilization, high reproduction rates, rapid development, transparency of the embryos and larvae, low maintenance cost, similar anatomy to mammals (with some exceptions), high tissue regeneration capacity, social behavior, $70 \%$ of genetic similarity with humans and $84 \%$ with human diseases-associated genes ${ }^{22}$. Streisinger et al. ${ }^{23,24,25}$ started the studies with zebrafish that confirmed the practicability of utilizing this model organism for the genetic analysis of vertebrate development. In kidney research, the zebrafish has emerged not only in developmental studies but also as a genetic tool in the search for new genes linked to kidney conditions ${ }^{26}$. Furthermore, the capacity of regeneration without scar formation and the ability to generate nephrons through their life, called neonephrogenesis, make the zebrafish a key animal model for regeneration research ${ }^{27,28}$. Moreover, the availability of experimental models for different kidney illness, including acute and chronic kidney injury, demonstrate the versatility of 
this experimental organism 26,29 . As in mammals, the renal progenitors of the zebrafish are derived from the intermediate mesoderm. Such renal progenitors generate the pronephros that will later develop to the mesonephros, which will be maintained as a mature organ until adulthood 29,30 .

The adult zebrafish kidney is located on the dorsal wall of the body, between the swim bladder and the backbone ${ }^{29}$. From a ventral view, the zebrafish can be segmented into three regions (Figure 1A): head $(H)$, trunk $(\operatorname{Tr})$, and tail $(\mathrm{Ta})^{29}$. Same as mammals, the zebrafish has the nephrons as functional units of the kidney, which are divided into tubule segments (Figure 1A): renal corpuscle (RC), proximal convoluted tubule (PCT), proximal straight tubule (PST), distal early (DE), late distal (DL) and collecting duct $(C D)^{29}$. Zebrafish shares genetic conservation and structural similarities with human nephrons (Figure 1B) but lacks some conformations such as the intermediate tubule, also known as the loop of Henle $(\mathrm{LH})^{29,31}$. Freshwater fishes like zebrafish are normally surrounded by a medium with very low osmolarity, because of this, they tend to be hyperosmotic and depend on the gills, the skin at early stages, and the kidney to regulate osmolarity and water excretion ${ }^{32}$. The filtration of blood from the dorsal aorta by the pronephros begins around $48 \mathrm{~h}$ post-fertilization (hpf) ${ }^{33,34}$. The kidney of the zebrafish is not only a metabolic waste excretion organ but also works as a hematopoietic organ from 4 days postfertilization (dpf) to adulthood and it is equivalent to the bone marrow in mammals ${ }^{35}$. During development, hematopoietic stem cells (HSCs) will seed the kidney, self-renovate, and generate myeloid, erythroid, and lymphoid cell lineages, maintaining transcription factors, signaling molecules, and highly conserved genetic programs with mammals ${ }^{36,37}$. Studies have revealed that most erythroid, thrombocytic, myeloid, and lymphoid cells of the human immune system are present in zebrafish ${ }^{37,38}$. The unique characteristics of this animal and the conserved features with the human kidney made this model organism advantageous in the research of kidney function, injury, and regeneration.

Although the kidney of the zebrafish is well studied and some models of $\mathrm{AKI}$ are already available in larva and adult zebrafish $^{28}$, at the time of the establishment of this protocol there was no evidence of a chemically-induced non-antibiotic AKI model in adult zebrafish. Besides this, our laboratory focuses on testing probiotic bacteria and microbiota-derived compounds to study regeneration and renal damage, thus we concentrated our efforts in creating a new cisplatin-induced AKI model in adult fishes. The video article presented in this manuscript demonstrates the procedures for a new model of AKI induction using an i.p. injection of 120 ug cisplatin per $\mathrm{g}$ of animal $(120 \mu \mathrm{g} / \mathrm{g})$ (Figure 2A). This dose was initially based on studies of $\mathrm{AKI}$ induced by cisplatin in murine models that went around $10 \mathrm{mg} / \mathrm{kg}$ (equivalent to $10 \mu \mathrm{g} /$ g) $14,15,16,17$, however, this dose was not sufficient to induce kidney damage related to nephrotoxicity (data not shown). Thus, we increased the dose to the ones used in this study (Figure 2B). Our work revealed a dose-dependent effect of cisplatin in survival rate after injection with induction of kidney tissue damage $24 \mathrm{hpi}$ as shown by loss of tubular structure, increased inflammatory infiltrate, and high rate of cell death. Here, we describe two techniques for analyzing the development of cisplatin-induced AKI: flow cytometry, to analyze cell infiltration, and TUNEL, to measure cell death. Flow cytometry is a technology that measures the physical (size and granularity) and chemical (fluorescent compounds) characteristics of the cells. Inside the cytometer the cell suspension runs through a sheath fluid that organizes the cells in a single line, allowing them to pass through a laser beam one cell at a time (Figure $3 \mathbf{A}$ ). A detector in front 
of the light beam will measure the Forward Scatter (FSC), which correlates with cell size, and detectors to the side will measure the Side Scatter (SSC) that correlates to the granularity of the cells. Other detectors will measure the fluorescence from particles, fluorescent-proteins, or antibodylabeled cells ${ }^{39,40}$. As commercial antibodies for zebrafish are scarce nowadays, the use of animal reporters and fluorescent biomarkers allows to improve this analysis and identify diverse cell populations $41,42,43$. Another tool used in this protocol was the Terminal deoxynucleotidyl transferase (TdT) dUTP Nick End Labeling (TUNEL) assay. The TUNEL assay is a late-stage apoptosis detection method that relies on the ability of the TdT to identify fragmented DNA and label it with deoxynucleotides tagged with a fluorescent marker that later can be visualized and quantified by microscopy ${ }^{44}$ (Figure 3B). Considering that one of the most striking features of $\mathrm{AKI}$ is the induction of apoptosis in tubular kidney cells ${ }^{3}$, this technique is extremely advantageous since it can be analyzed by flow cytometry and/or microscopy.

The approaches presented in this article allows the observation of the AKI status and offer a new acute model to study AKI disorders that can be useful for the research of new therapeutic targets in cisplatin-related AKI.

\section{Protocol}

The procedures described in this protocol were previously approved to be used in the zebrafish model by the Animal Use Ethics Committee of the Institute of Biomedical Sciences of the University of São Paulo.

\section{AKI Induction by Cisplatin Intraperitoneal Injection}

1. Prepare cisplatin working solution by diluting the stock solution to $850 \mu \mathrm{g} / \mathrm{mL}$ in $0.9 \% \mathrm{NaCl}$. Keep at room temperature, protected from light.

CAUTION: The fabricant recommends the manipulation of cisplatin with personal protective equipment (PPE) including goggles, gloves, and lab coat. Store the stock solution at room temperature, protected from light.

2. Prepare $150 \mathrm{mg} / \mathrm{L} \mathrm{MS}-222$ (Tricaine) anesthetic in system water ${ }^{45}$. Anesthetize adult zebrafish months) by immersion for approximately 1-2 min.

NOTE: Effectively anesthetized fish should be irresponsive to touch. To test effective anesthesia, gently press the caudal fin to observe reaction.

CAUTION: Tricaine is an irritant to the skin and eyes, use PPE to manipulate.

3. Using a plastic spoon transfer the fish to an absorbent surface, such as paper towels, to remove excess water around the body. Then, with the plastic spoon transfer the fish to a Petri dish over a scale and weigh the fish. Take note of the weight of the fish as it will be necessary for dose calculations.

NOTE: Absorbing excess water from fish prevents overestimate the animal's weight, do not over-dry since is prejudicial to the fish.

4. To achieve the final dose of $\mathbf{1 2 0} \boldsymbol{\mu g} / \mathrm{g}$ of weight, divide the $\mu \mathrm{g}$ of the final dose $(120 \mu \mathrm{g})$ per the $\mu \mathrm{g}$ of the cisplatin working solution $(850 \mu \mathrm{g})$ and convert this number to microliters $(\mu \mathrm{L})$ by multiplying for 1000 , to get the volume of $120 \mu \mathrm{g}$ of cisplatin $(141.2 \mu \mathrm{L})$. Then multiply this number $(141.2 \mu \mathrm{L})$ for the weight of the fish (g) to get the final volume to be injected. 
5. With a plastic spoon, transfer the fish on a wet sponge with a little cut to hold it, with the ventral side up. The sponge should be wet with anesthetic in system water.

6. Fill a $31 \mathrm{G} 1.0 \mathrm{~mL}$ insulin syringe with the calculated volume of cisplatin working solution.

7. Insert the needle into the animal's intraperitoneal portion near the pelvic fin, at a shallow angle to avoid puncturing the viscera (Figure 2A). Then slowly inject the solution.

8. After injection place the fish in a tank to recover from anesthesia. Watch the fish for signs of normal recovery (e.g., swimming movements, opercular movements).

NOTE: The animal should recover in the next 3-5 min. If necessary, stimulate the fish by moving it with a plastic spoon, a Pasteur plastic pipette, or putting it close to a hose with bubbles.

9. For control fish, perform the same procedure by injecting a solution of $0.9 \% \mathrm{NaCl}$. Use the same calculation following the proportion of body weight: the volume to be injected will be $141 \mu \mathrm{L}$ multiplied by the weight of the fish (g).

10. Monitor survival of fish at least twice a day in the following days (Figure 2B).

\section{Kidney Isolation and Tissue Processing for Flow Cytometry of Immune Cells}

1. For this procedure, use immune cell-fluorescent marked transgenic animals (e.g., $\operatorname{Tg}(m p o: G F P))$.

2. After $24 \mathrm{hpi}$ of $120 \mu \mathrm{g} / \mathrm{g}$ cisplatin, euthanize animals by hypothermal shock (rapid chilling).

NOTE: Hypothermal shock has been demonstrated to be more effective as euthanasia method than MS-222 overdose. Hypothermal shock is less stressful, fast, consistent, and safer for personnel than the use of MS-222, has previously described 46,47 .

3. In an outer crossing tank prepare ice-water in a 5:1 ratio of ice to system water, put the inner tank with a screen over the ice, wait until water reaches $2-4^{\circ} \mathrm{C}$.

NOTE: Fishes should not be in direct contact with the ice, because this may cause thermal burns and pain.

4. Transfer animal to ice-water, wait at least $10 \mathrm{~min}$ until there is loss of orientation and no opercular movement.

5. With a plastic spoon, place the fish on paper towels to dry off the excess water.

6. Transfer the fish to a $3 \%$ agarose dissection plate and take it under a stereoscope with upper light. With scissors, decapitate fish making a fast cut just behind the eyes, and remove the head.

7. With fine scissors make a cut from the open side to the cloaca and remove the internal organs with fine forceps.

8. Use insect pins to pinch the sides of the body walls to open the carcass and expose the kidney attached to the backbone.

9. Detach the kidney with fine forceps and place the organ in a 6 well plate with a cold solution of $1 \times \mathrm{PBS} / 2 \%$ FBS. Keep on ice.

10. Pick up the tissue with a Pasteur plastic pipette and pass the tissue through a $40 \mu \mathrm{m}$ cell strainer over a $50 \mathrm{~mL}$ tube, gently macerating it with a syringe plunger.

11. Wash twice with $1 \mathrm{~mL}$ of $1 \times \mathrm{PBS} / 2 \% \mathrm{FBS}$ and collect the cells in a $50 \mathrm{~mL}$ tube.

12. Centrifuge cells at $400 \times \mathrm{g}$ for $5 \mathrm{~min}$ at $4{ }^{\circ} \mathrm{C}$.

13. Carefully pick up all the supernatant with a $1 \mathrm{~mL}$ micropipette and discard it. Add $500 \mu \mathrm{L}$ of cold 1x PBS 
to resuspend the cells and place them in $5 \mathrm{~mL}$ flow cytometry tubes. Keep on ice.

14. Count cells in Neubauer chamber making a 1:10 dilution in Trypan Blue (e.g., take $10 \mu \mathrm{L}$ of the sample and mix with $90 \mu \mathrm{L}$ of Trypan Blue). Add $10 \mu \mathrm{L}$ of the mixture to a Neubauer chamber and count cells under the microscope.

NOTE: Optimal results are expected with $1-5 \times 10^{6}$ cells/ $\mathrm{mL}$ and $>80 \%$ viability.

CAUTION: Trypan blue is a carcinogenic agent, use PPE to handle.

15. Take the cells to be read by a cytometer. Then analyze the results selecting the population of interest.

\section{Processing of Adult Zebrafish Kidney Tissue for TUNEL Assay}

1. For this procedure, use wild-type animals (e.g., $A B$, Tübingen, etc.) or a transgenic animal with different fluorescent color than the TUNEL kit, as similar fluorescence can interfere with TUNEL's analysis.

2. After $24 \mathrm{hpi}$ of $120 \mu \mathrm{g} / \mathrm{g}$ cisplatin, euthanize animals by hypothermal shock (rapid chilling). See 2.3-2.4.

3. Dissect the fish as described in 2.5-2.6; the kidney must remain attached to the backbone during the fixation procedure (explained below).

4. Using insect pins, pinch the sides of the body walls to open the carcass and pin it on a cork surface to keep the kidney exposed.

NOTE: This procedure ensures that the kidney remains in the right position for later analysis.

5. Then place the cork surface with the kidney facing down in a 6 well plate over a freshly made solution of $4 \%$ paraformaldehyde (PFA). Keep it overnight at $4{ }^{\circ} \mathrm{C}$.
CAUTION: PFA is carcinogenic and irritant for skin and mucous surfaces. Prepare PFA solutions under a chemical hood using PPE including eye protection equipment.

6. The next day, dissect the kidneys as in 2.8. Place the kidneys in a $60 \mathrm{~mm}$ Petri dish with 1x PBS and rinse twice in $1 \times$ PBS.

7. Prepare $2 \%$ agarose to generate a support matrix for the tissue.

8. Discard all remaining $1 \times$ PBS from the Petri dish and pour $2 \%$ agarose slowly to cover the whole organ. Then position the kidney using fine forceps under a stereomicroscope to prevent the kidney to fold. Let agarose solidify at room temperature.

NOTE: This procedure will keep the orientation and shape of the organ through histological processing since the leaf-like shape of the organ causes a tendency to fold if it is not inside a supportive matrix.

9. After agarose solidification, use a scalpel to cut the agarose around the tissue, forming small cubes, and remove the excess of agarose around the tissue.

10. Place the agarose cubes in a cassette suitable for histological processing.

NOTE: The following steps can be done manually or in an automatic tissue processor.

11. First, process the tissue in the cassette following the next steps for $45 \mathrm{~min}$ each at room temperature: one bath of $50 \%$ ethanol, one bath of $70 \%$ ethanol, two consecutive baths of $95 \%$ ethanol, and three consecutive baths of $100 \%$ ethanol. Afterward, process the tissue in two consecutive baths of Xylene and three consecutive baths of paraffin; the latter lasts 1 hour each at $60{ }^{\circ} \mathrm{C}$. 
CAUTION: Make changes under a chemical hood, vapors from ethanol and xylene are irritant and toxic.

12. To prepare paraffin blocks, melt paraffin lentils to $60^{\circ} \mathrm{C}$.

13. Open the plastic cassette with the tissue inside and keep it on a warm plate. Warm-up metal molds for the paraffin.

14. With tweezers place the tissue over a metal mold so that the kidney length is parallel to the mold base. Add the paraffin, reallocate the tissue if necessary.

15. Cover the mold with the base of the cassette and add paraffin until the grid is covered. Let solidify at room temperature and then place at $-20{ }^{\circ} \mathrm{C}$ for a faster solidification process.

16. Release paraffin block from the metal mold around $20-30$ min later.

17. With a microtome, section the tissue embedded in paraffin to $5 \mu \mathrm{m}$ thickness. Use silanized or positively charged glass slides to collect the tissue.

\section{TUNEL assay}

NOTE: The following protocol uses an In Situ Cell Death Detection Kit (Table of Materials).

1. Dewax tissue slides placing them in two consecutive baths of xylene for $5 \mathrm{~min}$. Then rehydrate the tissue through a graded series of ethanol: 100\%-95\%-70\%-50\%, for 5 min each.

2. Place slides in running cold tap water to rinse off the ethanol. Keep the slides in distilled water.

3. Prepare a dark incubator chamber. Add wet paper towels on the bottom to keep the moisture during the incubation steps.
NOTE: In lack of an incubator chamber is possible to use a Petri dish with moist paper in the bottom and two toothpicks to place the slide.

4. Prepare fresh Proteinase K working solution: $10 \mu \mathrm{g} /$ $\mathrm{mL}$ in $10 \mathrm{mM}$ Tris/HCl, $\mathrm{pH}$ 7.4-8.

NOTE: Proteinase $\mathrm{K}$ is used as a permeabilization agent, as recommended by the fabricant.

5. Place the slides in the dark incubator chamber and add Proteinase $\mathbf{K}$ working solution until cover samples. Incubate for $30 \mathrm{~min}$ at $37^{\circ} \mathrm{C}$.

6. While samples are incubating, prepare the TUNEL reaction mixture: Add $50 \mu \mathrm{L}$ of Enzyme Solution to 450 $\mu \mathrm{L}$ Label Solution. Protect from light.

NOTE: The volume to be prepared can be adjusted in the same 1:10 proportion. The volume is calculated to be $50 \mu \mathrm{L}$ of the mixture for each section; this can change depending on the size of the samples.

7. Pick up the dark chamber and wash the slides twice with $1 \times$ PBS.

8. Next, dry the region around the sample using absorbent paper and add $50 \mu \mathrm{L}$ of TUNEL reaction mixture over each tissue slide, spread the solution so that the whole sample is covered. Incubate at $37^{\circ} \mathrm{C}$ for $2 \mathrm{~h}$. Protect from light.

9. After incubation, rinse the slide three times with $1 x$ PBS and dry the region around the sample using paper towels.

10. Add $50 \mu \mathrm{L}$ of DAPI $1: 1000$ to the samples, for nuclear counterstaining, and incubate for $5 \mathrm{~min}$ at room temperature. Protect from light.

11. Rinse again three times with $1 x$ PBS and dry the region around the sample. 
12. Mount the slide with an anti-fade hydrophilic medium, place a coverslip, and seal with nail polish. Store slides horizontally, protected from light at $4{ }^{\circ} \mathrm{C}$.

NOTE: The anti-fade properties of the mounting medium are to preserve the fluorescence of the samples but is possible to use any hydrophilic medium available. The final sealing step with nail polish is crucial to avoid dehydration.

13. Visualize the samples under a fluorescence microscope. For this type of fluorescent pigment, use an excitation wavelength in the range of $520-560 \mathrm{~nm}$ (green) and detection in the range of $570-620 \mathrm{~nm}$ (red).

\section{Representative Results}

The kidney of the zebrafish is a flat pigmented organ located on the dorsal wall and its basic functional unit, the nephron, is conserved with mammals (Figure 1). The particularity of having just one kidney with a high capacity of regeneration makes this model organism an excellent choice for model kidney injury. The protocols presented in this work are designed to induce AKI by the intraperitoneal (i.p.) injection of cisplatin in adult zebrafish (Figure 2) and to later be analyzed by two techniques detailed before: flow cytometry (Figure 3A) and TUNEL (Figure 3B). A flowchart of the whole process is depicted in Figure 4. The doses of cisplatin were applied based initially on those described in mouse models $^{15,16,17}$, in which the standard used is $10-13 \mathrm{mg}$ of cisplatin per $\mathrm{kg}$ of animal $(\mathrm{mg} / \mathrm{kg}$ ). However, the zebrafish showed to be more resistant to cisplatin than the mouse (data not shown), and the final dose was increased. When we evaluated the survival rate of the animals, the experiments showed a dose-dependent effect of cisplatin (Figure 5A). Because of this, we recommend following the instructions exactly as explained in this protocol and monitor the survival rate of the animals constantly as a measure of reproducibility, before collecting any material. After the i.p. injection of 120 $\mu \mathrm{g} / \mathrm{g}$ cisplatin (Figure 5A, red line), a decrease in survival of around $30 \%$ of the animals was observed in the first 24 $\mathrm{h}$ and the survival decreased gradually until reaching around $20 \%$ of live animals on day 5 post-injection, then stabilized (Figure 5A). Cisplatin toxicity was not affected by the sex of the animals, since males and females have similar survival curves (Figure 5B).

Analysis of the kinetics of cisplatin-induced AKI showed increased inflammation and cell death in the kidney 24 hpi. One of the fastest and quantitative ways to evaluate inflammation is flow cytometry but given the lack of antibodies against zebrafish antigens available commercially for this technique, is necessary to use a transgenic line with an immune marker. Nowadays, many zebrafish lines labeling immune cells are accessible (Table 1). These lines can be singly used or in combination, given enough repertoire for analysis $48,49,50,51,52,53,54,55,56,57,58,59,60$. This simplifies enormously the technique since is not necessary any antibody incubation step, on the contrary, after the isolation of the cells by mechanical separation, the direct reading on the cytometer is possible.

As mentioned before, the kidney of the zebrafish is not only a blood filtration organ with homeostatic functions but also the anatomical site of hematopoiesis in adults, equivalent to the bone marrow in mammals $33,34,35$. This way when we analyze it by flow cytometry is possible to differentiate cell populations comparable to the human blood ${ }^{61,62}$ (Figure 6A), this allows us to identify the cell populations initially by size and granularity and exclude debris. In this case, we used a transgenic line called $T g(m p o: G F P)^{52}$ that expresses a green fluorescent protein (GFP) together with the enzyme 
myeloperoxidase, which is present in neutrophils. Knowing this, our gate strategy was based on the initial separation of the granulocyte's population (Figure 6B). Following this, doublet cells were excluded, since they can significantly alter the analysis and lead to inaccurate conclusions. A doublet is a single event that consists of 2 independent particles and can be excluded by selecting a forward scatter height (FSCH) vs. a forward scatter area (FSC-A) density plot (Figure 6C). After this step, the cells that expressed the fluorescent marker were identified and selected (Figure 6D). Finally, the population statistics were extracted from the analysis and plotted as percentage of cells (Figure 6E).

One of the most prominent characteristics of cisplatin nephrotoxicity is tubular cell death ${ }^{10}$, and to easily visualize this we used the TUNEL assay for apoptosis detection. This method recommends using wild-type cells and tissues that lack fluorescent markers, since parallel fluorescence would interfere with the analysis, in the case of the zebrafish is recommended to use wild-type lines, such as $A B$, Tübingen, $\mathrm{TAB}$, or a transgenic line with a fluorescent protein that does not interfere with the TUNEL fluorescence color. The TUNEL technique allows the analysis via flow cytometry or microscopy. Microscopy has the advantage of conserving the tissue structure, allowing to see which cells are dying. Under the fluorescent microscope, the bright nuclei of apoptotic cells can be easily differentiated from the background. Animals injected with cisplatin (Figure 7B) have more dead cells than the control (Figure 7A) at $24 \mathrm{hpi}$. The final quantification was made with the cell-counter option of FIJI Software and showed statistically more dead cells in cisplatin-treated kidneys than in the controls (Figure 7C)

The protocol described in this manuscript showed how to use cisplatin as an inducer of $\mathrm{AKI}$ in adult zebrafish, which is dose-respondent, fast, and reliable. Based on the data obtained from survival rates and the measurement of signs of nephrotoxicity of cisplatin including inflammation (detected by flow cytometry) and cell death (detected by TUNEL assay), we propose this model for the study of cisplatin nephrotoxicity as well as for future treatments in AKI-related diseases. 


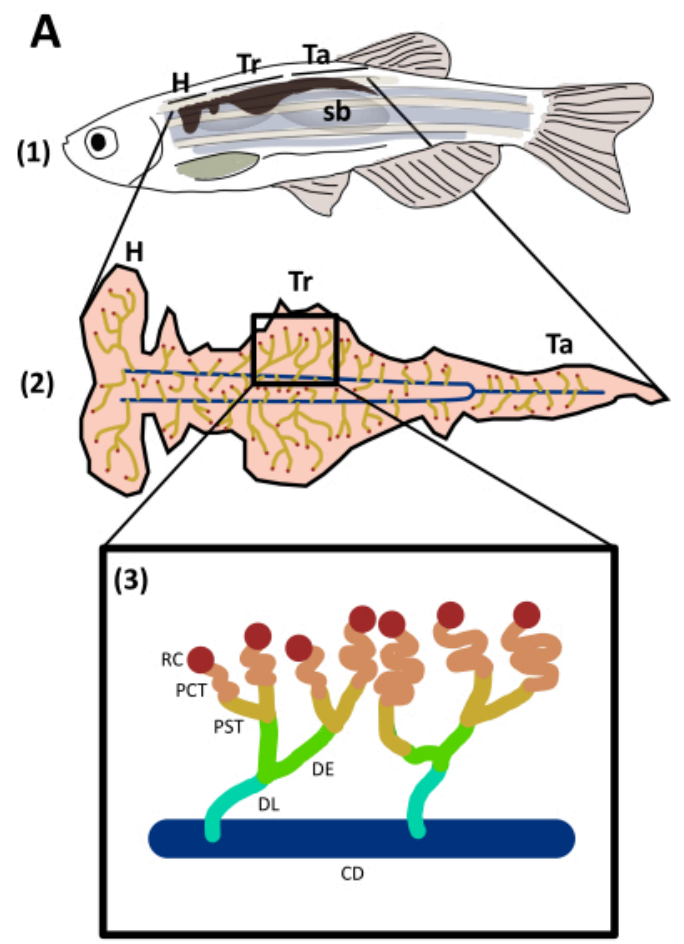

B

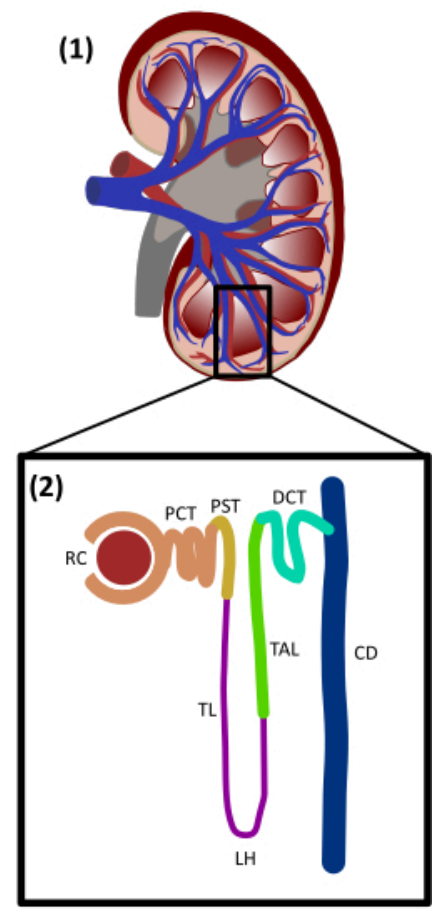

Figure 1: Structure and comparison of zebrafish and human kidneys. A. (1) Lateral view of an adult zebrafish with the kidney represented in dark brown located in the dorsal wall of the fish, between the swim bladder (sb) and the backbone. (2) Ventral view of the kidney showing nephrons (yellow) connected to the collecting duct (blue). The different regions of the kidney are flagged: head $(\mathrm{H})$, trunk $(\mathrm{Tr})$, and tail $(\mathrm{Ta})$. (3) Schematic representing zebrafish nephrons and their segments labeled and colored to match genetic conserved regions with human nephron. B. (1) Sagittal view of a human kidney. (2) Schematic depicting a human nephron with segments labeled and colored. RC: renal corpuscle; PCT: proximal convoluted tubule; PST: proximal straight tubule; TL: thin limb; LH: Loop of Henle; TAL: thick ascending limb; DE: distal early; DL: distal late; DCT: distal convoluted tubule; CD: collecting duct. Please click here to view a larger version of this figure. 


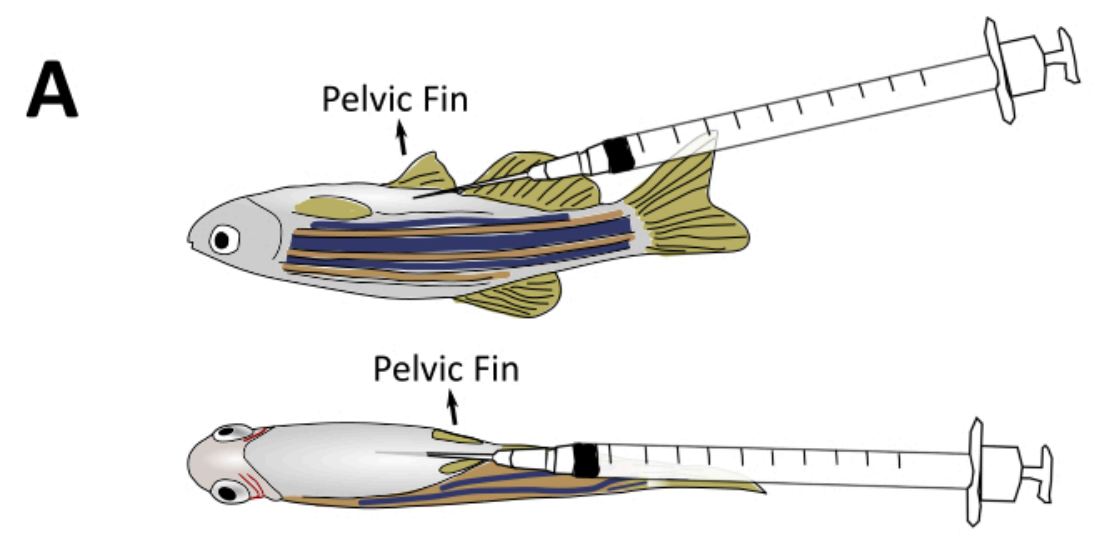

B

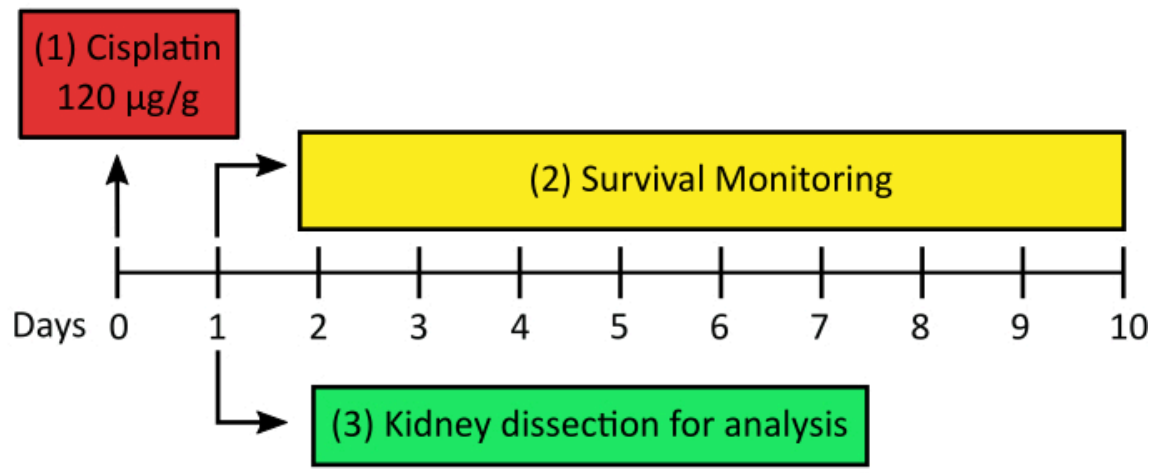

Figure 2: Experimental design for cisplatin-induced AKI. A. Lateral and ventral view of adult zebrafish pointing the position of the needle during the injection procedure. The needle penetrates at a $20-30^{\circ}$ angle from the belly and is inserted slowly parallel to the ventral wall avoiding puncturing the viscera. B. Experimental design of cisplatin-induced AKI: (1) Injection of cisplatin $120 \mu \mathrm{g} / \mathrm{g}$ per animal at day zero. (2) Before attempting step 3, survival monitoring of fishes after injection is recommended from day one until day ten. (3) Kidney dissections one day after cisplatin injection for further processing techniques. Please click here to view a larger version of this figure. 
$\mathbf{A}$

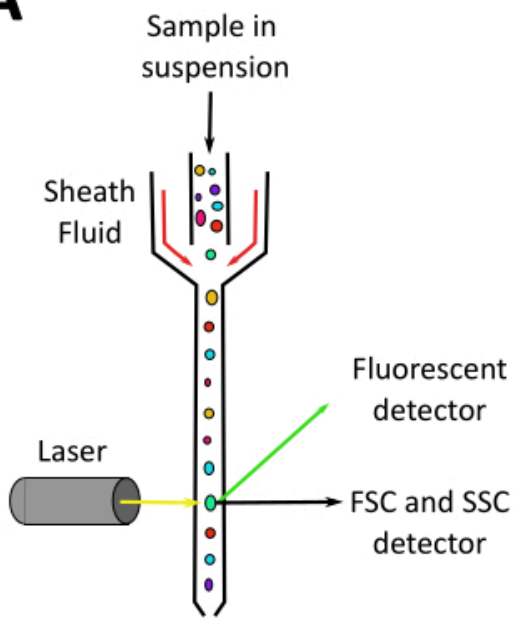

B

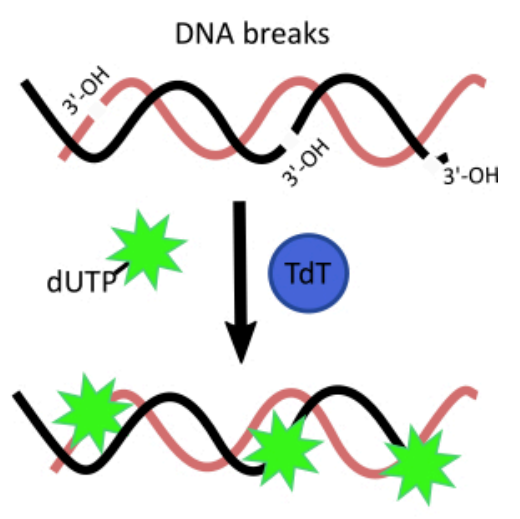

Figure 3: Mechanisms of flow cytometry and TUNEL techniques. A. Overview of the flow cytometer: a suspension of cells is hydrodynamically focused on a single line by a sheath fluid, causing cells to pass one by one in front of a laser beam. Detectors in front and on the side measure the forward scatter (FSC), side scatter (SSC), and fluorescence of the cells. B. Principle of TUNEL assay. Terminal deoxynucleotidyl transferase (TdT) mediates the addition of a fluorescent-marked dUTP to $3^{\prime}-\mathrm{OH}$ ends of a fragmented DNA. Please click here to view a larger version of this figure. 


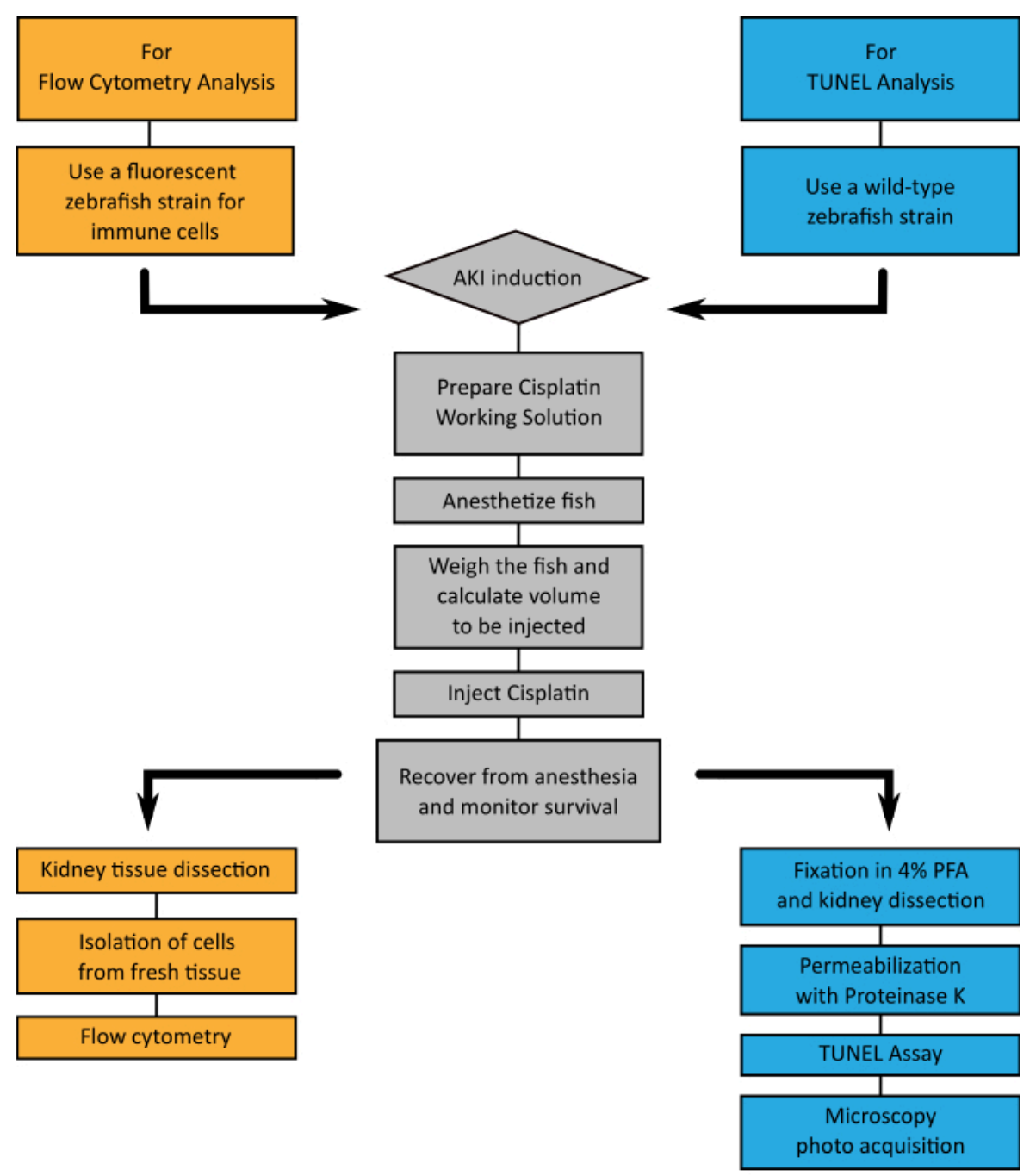

Figure 4: Flowchart of represented techniques. A. A flowchart showing the steps to follow when choosing to analyze the kidney tissue through flow cytometry (orange) or TUNEL (blue), when inducing AKI by cisplatin injection (grey). Please click here to view a larger version of this figure. 
A

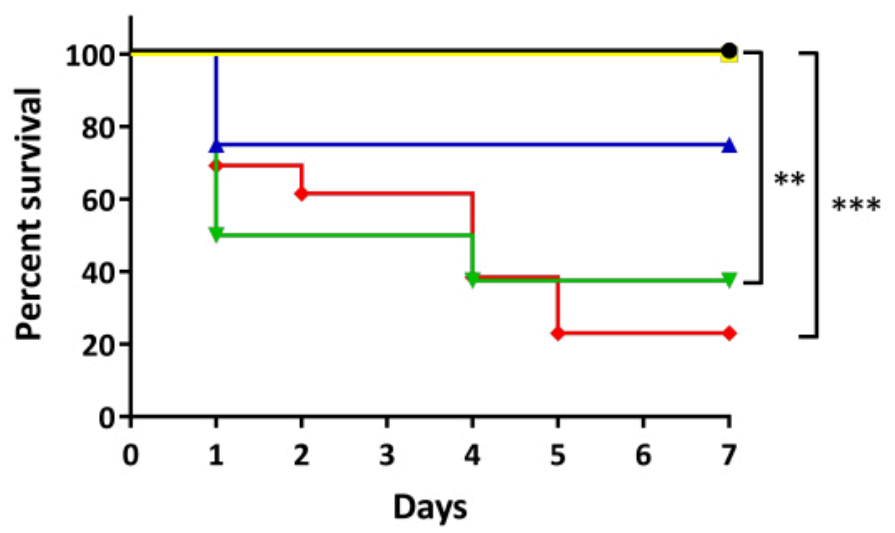

Control $(\mathrm{n}=9)=$ Cisplatin $25 \mu \mathrm{g} / \mathrm{g}(\mathrm{n}=8) \neq$ Cisplatin $50 \mu \mathrm{g} / \mathrm{g}(\mathrm{n}=8)$

$\rightarrow$ Cisplatin $112.5 \mu \mathrm{g} / \mathrm{g}(\mathrm{n}=8) \rightarrow$ Cisplatin $120 \mu \mathrm{g} / \mathrm{g}(\mathrm{n}=13)$

B

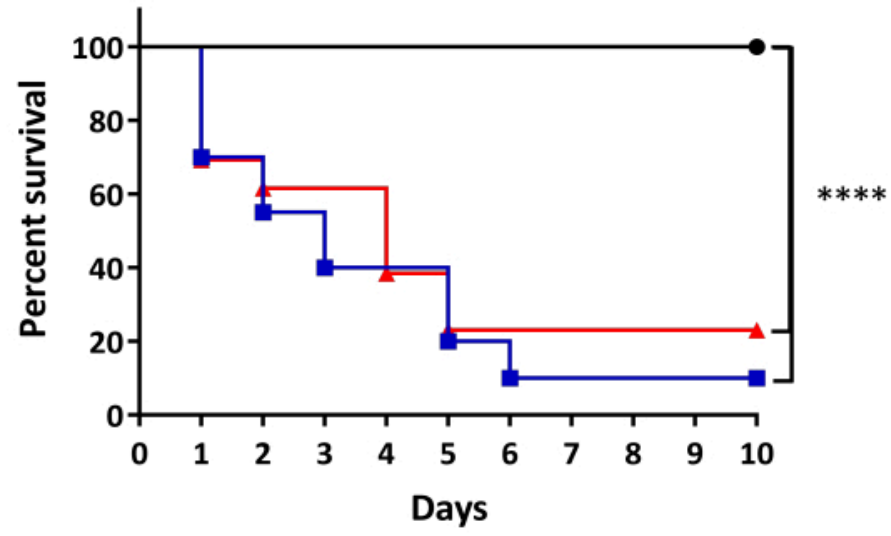

$\rightarrow$ Control $(n=20) \rightarrow$ Cisp Male $(n=20) \leftarrow$ Cisp Female $(n=13)$

Figure 5: Survival monitoring of cisplatin injected fish. A. Survival rate of different dosages of cisplatin injections (25 $50-112.5-120 \mu \mathrm{g} / \mathrm{g}$ ). Log-rank (Mantel-Cox) test, ${ }^{* *} p<0.01$. B. Survival rate of males vs. females injected with $120 \mu \mathrm{g} / \mathrm{g}$ cisplatin. Log-rank (Mantel-Cox) test, ${ }^{* * *} p<0.001$. Please click here to view a larger version of this figure. 

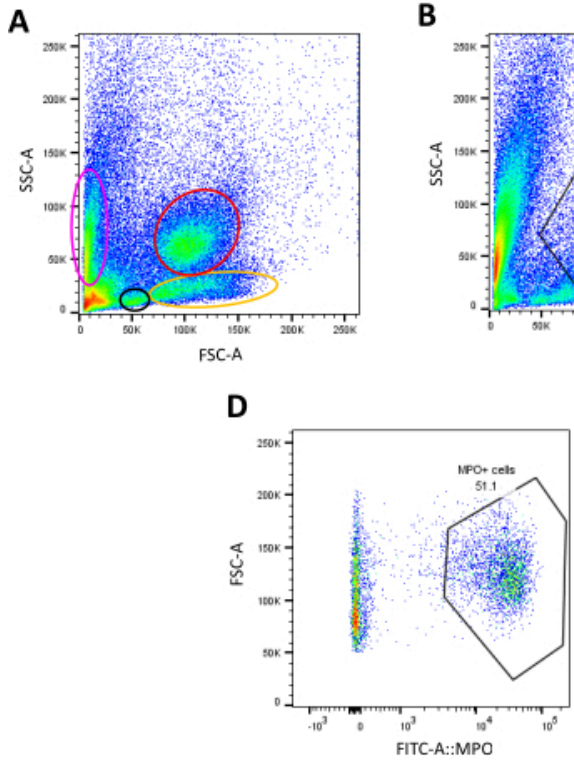

B

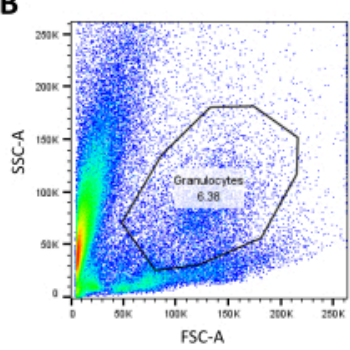

C

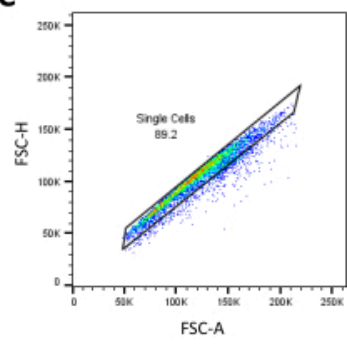

E

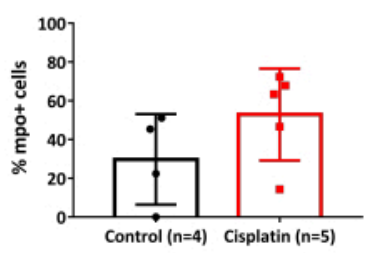

Figure 6: Gate strategy for transgenic zebrafish line. A. Density plot of zebrafish adult kidney cells, populations are separated by size (FSC-A) and granularity (SSC-A). Different populations are selected by colored ovals/circles. Pink: Erythroid; Black: Lymphoid; Yellow: Precursors; Red: Granulocytes. B. Density plot of side scatter area (SSC-A) and forward scatter area (FSC-A) for selection of Granulocytes population in the kidney. C. Density plot of forward scatter high (FSCH) and forward scatter area (FSC-A) for selection of singlets population inside the granulocyte gate. D. Density plot of forward scatter area (FSC-A) and FITC-A:MPO for selection of mpo:GFP positive cells (neutrophils) in the kidney. A positive population is considered around $10^{3}$ on, of fluorescence intensity. E. Graph of the percentage of mpo:GFP positive cells (neutrophils) in Control vs. Cisplatin animals, $24 \mathrm{hpi}$. Unpaired $t$-test. Please click here to view a larger version of this figure. 

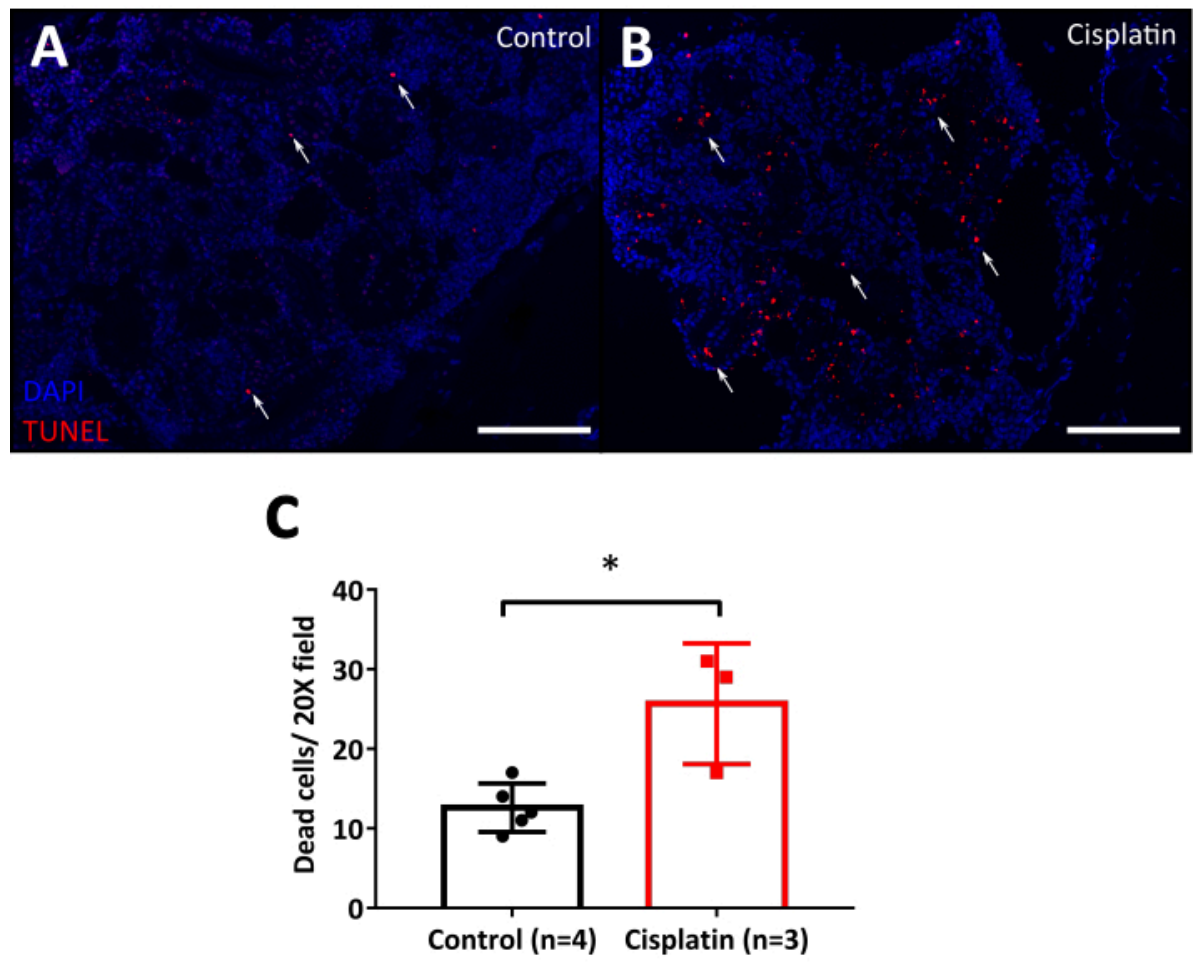

Figure 7: TUNEL assay of cisplatin injected fish. A. Microphotographs of fixed adult kidney $24 \mathrm{~h}$ after $120 \mu \mathrm{g} / \mathrm{g}$ cisplatin injection. Controls are injected with $0.9 \% \mathrm{NaCl}$. TUNEL positive cells (apoptotic cells) are stained in red (white arrows). DAPI (blue) is used as a nuclear counterstain. Scale bar: $50 \mu \mathrm{m}$. 20x magnification. B. Graph showing quantification of the number of dead cells in the kidney by $20 x$ field. Unpaired $t$-test, ${ }^{*} p<0.05$. Please click here to view a larger version of this figure. 


\begin{tabular}{|c|c|c|}
\hline Transgenic Line & Cell Type Labeled & References \\
\hline Tg(spi1:EGFP)pA301 & Myeloid cells & Ward et al. $2003^{48}$ \\
\hline $\operatorname{Tg}(z p u 1: G F P)$ & Myeloid cells & Hsu et al. $2004^{49}$ \\
\hline $\operatorname{Tg}(m h c 2 d a b: G F P) s d 6$ & Monocytes & Wittamer et al. 201150 \\
\hline Tg(lysC:DsRED2) & Neutrophils & Hall et al. $2007^{51}$ \\
\hline $\operatorname{Tg}(m p o: G F P)$ & Neutrophils & Mathias et al. $2006^{52}$ \\
\hline Tg(mpeg1:mCherry) & Macrophages & Ellett et al. $2011^{53}$ \\
\hline $\operatorname{Tg}(m p e g 1: D e n d r a 2)$ & Macrophages & Harvie et al. $2013^{54}$ \\
\hline$T g(I c k: G F P)$ & T-cells & Langenau et al. $2004^{55}$ \\
\hline TgBAC(ikaros:EGFP) & T-cells & Bajoghli et al. $2009^{56}$ \\
\hline $\operatorname{Tg}($ rag1:GFP) & T-cells & Jessen et al. $1999^{57}$ \\
\hline $\operatorname{Tg}($ rag2:GFP) & T-cells & Jessen et al. $2001^{58}$ \\
\hline $\operatorname{Tg}(C D 79: G F P)$ & B-cells & Liu et al. $2017^{59}$ \\
\hline $\operatorname{Tg}(C D 45: D s R e d)$ & Leukocytes & Bertrand et al. $2008^{60}$ \\
\hline
\end{tabular}

Table 1: Zebrafish transgenic lines for immune cells. Table resuming the names of zebrafish reporter lines with the respective type of immune cell labeled and the reference articles where they were constructed. A combination of these zebrafish lines can offer new possibilities of cell selection by flow cytometry.

\section{Discussion}

The prevalence of kidney disease has continued to increase worldwide, becoming a global public health problem that affects millions of people ${ }^{63}$. Finding a way to treat kidney injured individuals is of paramount importance as well as understand more about their etiology and progression. Several studies have been using animal models to understand renal damage. The zebrafish kidney (Figure 1) has been studied for years in developmental biology and injury research because of its self-regenerating capacities and genetic similarity ${ }^{29,64}$. Here, we present a new AKI model in adult zebrafish using the properties of cisplatin as a nephrotoxic agent, detailing the steps for accomplishing a fast and acute reaction with damage visible as soon as $24 \mathrm{hpi}$ (Figure 2). Moreover, here we explain two techniques that will help to the evaluation of the tissue damage after the cisplatin injection, flow cytometry and TUNEL (Figure 3).

Current AKI models in adult zebrafish include the i.p. injection of gentamicin which induces extensive damage in the nephron and tubule destruction, neonephrogenesis 
events start from day 5 , and regeneration is completed by 21 days post-injection ${ }^{65}$. On the other hand, a model of sepsisassociated acute kidney injury (S-AKI) was established by the infection with Edwardsiella tarda, since significantly increased the expression of AKI markers, such as insulin-like growth factor-binding protein-7 (IGFBP7), tissue inhibitor of metalloproteinases 2 (TIMP-2), and kidney injury molecule-1 (KIM-1), in larvae and adult zebrafish ${ }^{66}$. The zebrafish is known for being a high-throughput animal for the search of therapeutic agents and this includes the use of probiotics and microbiota-derived metabolites to study kidney function and regeneration ${ }^{67}$. However, the available models could directly affect the outcome of these treatments. Thus, we established a different method to induce AKI in adult zebrafish (Figure 4), using cisplatin as a known nephrotoxic agent that would not have direct known effects on the fish microbiota, as would the gentamicin model for being an antibiotic, or the infection with E. tarda, for being a sepsis model. However, at the same time that we were developing our cisplatin protocol, another group also explored the nephrotoxic effects of cisplatin in adult zebrafish, simplifying the dose to $10-20-30 \mu$ per animal $^{68}$. Although they also showed cisplatin dose-dependent effect in survival, we recommend caution in using a single quantity of cisplatin for all fishes, as zebrafish from the same age can have very different sizes and weight and this could induce variations in the results 69,70 . We think is important to adjust the dose to the corresponding weight of the animal, as is done in mice and this study.

In our experiments with adult zebrafish, cisplatin showed a dose-response effect. This was visualized by monitoring the survival rate of the animals after cisplatin injection (Figure 5). We used survival as a way of estimate the intensity of the dose of cisplatin and not as a measure of nephrotoxicity, as no other physical sign is visible during the monitoring time.
This can be comparable with rodents, in which the severity of the kidney injury can be modulated by the dosage and frequency of cisplatin injection ${ }^{15}$, achieving lethal doses with higher concentrations of cisplatin ${ }^{71}$. Dead is also seen in the following days in the larval model of cisplatin ${ }^{72}$. Since our aim was to induce an acute injury in few days, we selected the $120 \mu \mathrm{g} / \mathrm{g}$ dose of cisplatin as is possible to observe kidney damage $24 \mathrm{~h}$ after the injection, however, this can be adjusted depending on the objectives of the study.

In humans, AKI is clinically diagnosed by decreased glomerular filtration rate (GFR), elevated serum creatinine, and blood urea nitrogen ${ }^{3}$. In zebrafish, the repertoire of AKI models includes some genetic-conditional models ${ }^{73,74}$ and some drug-related models ${ }^{65,72}$, but as some of the AKI functional parameters cannot be measured on zebrafish because of technical difficulties (e.g., blood collection), most research adopts morphological and visual techniques to observe the features of $\mathrm{AKI}^{1,75}$ such as our study.

In rodents, cisplatin enters the epithelial cells in the proximal and distal tubules, inside the cell undergoes metabolic activation and becomes highly reactive acting on cell organelles and inducing changes in cell structure. These changes can induce apoptosis and autophagy and even necrosis, at very high doses. In response to this damage, many cytokines are released and leukocytes are recruited leading to inflammation and affecting the functionality of the organ $^{15}$. This highlights the importance of assessing what type of cells can be found in the injured kidney, as residents or infiltrated immune cells. Here we showed how to assess this by flow cytometry, using the transgenic immune reporter lines available nowadays (Table 1). Cisplatin increased the percentage of neutrophils (mpo:GFP positive cells) in the kidney $24 \mathrm{~h}$ after the injection (Figure 6). In the case of the 
zebrafish, the kidney is the niche of HSCs that give rise to different blood cell types. Nonetheless, many granulocytes and macrophages are normally circulating in the blood. In our example, we used the mpo:GFP transgenic line that express GFP under the promoter of myeloperoxidase of neutrophils $^{52}$. Original studies of the mpo:GFP transgenic line demonstrated expression of myeloperoxidase in different states of neutrophil maturation ${ }^{76}$ but our gate strategy focused on the granulocyte fraction that comprises mature cells coming from the blood ${ }^{52}$, this way our analysis include infiltrated cells and not resident cells. This is important to consider when isolating the desired cell population.

As explained above, apoptosis is the most classic marker of cisplatin-related AKI. Here, we demonstrated a simple protocol for the localization of dead cells by the TUNEL assay. Cisplatin injection increased the number of apoptotic cells 24 hpi (Figure 7). This can be easily quantified by counting directly the dead cells from the tissue. Nonetheless, for the identification of cell-specific death the use of antibodies against the desired cell (e.g., tubular cells), or the use of a transgenic reporter line can be used together with this technique. When compared with the gentamicin-induced model of AKI, cisplatin seems to be a more severe model, since gentamicin apoptosis was higher on the third day after injection $^{65}$.

Despite having a variety of side effects, cisplatin is still widely used in cancer therapy, because of its effectiveness against various types of cancers, including carcinomas, germ cell tumors, lymphomas, and sarcomas ${ }^{77}$. Nephrotoxicity occurs in one-third of patients in treatment with cisplatin ${ }^{10}$, thus the search for strategies that can decrease this effect and increase renoprotection is imperative. We believe that the methods and techniques presented in this manuscript will help to elucidate mechanisms of kidney injury and find therapeutic targets that can be essential to improve the quality of life of individuals that suffer from renal complications, predominantly the ones related to the use of cisplatin.

\section{Disclosures}

The authors have nothing to disclose.

\section{Acknowledgments}

This research was supported by Fundação de Amparo à Pesquisa do Estado de São Paulo - FAPESP (2015/21644-9; 2017/05264-7; 2017/05687-5; 2018/20722-4), Conselho Nacional de Desenvolvimento Científico e Tecnológico (CNPq) and Coordenação de Aperfeiçoamento de Pessoal de Nível Superior (CAPES), financial code 001. We thank to our collaborators at the Laboratory of Maria Rita dos Santos e Passos-Bueno's and the Zebrafish Facility of the Genetics and Evolutionary Biology Department, in the Bioscience Institute of the University of São Paulo. We kindly thank Cristiane Naffah de Souza Breda and Theresa Raquel de Oliveira Ramalho for the comments and suggestions on the manuscript. We greatly appreciate and thank Marcio Villar Martins, from the multimedia team of the Institute of Biomedical Sciences, for the recording, edition, and production of this video.

\section{References}

1. McKee, R.A., Wingert, R.A. Zebrafish Renal Pathology: Emerging Models of Acute Kidney Injury. Current Pathobiology Reports. 3 (2), 171-181 (2015).

2. Guo, C., Dong, G., Liang, X., Dong, Z. Epigenetic regulation in AKI and kidney repair: mechanisms and therapeutic implications. Nature Reviews Nephrology. 15 (4), 220-239 (2019). 
3. Makris, K., Spanou, L. Acute Kidney Injury: Definition, Pathophysiology and Clinical Phenotypes. Clinical Biochemist Reviews. 37 (2), 85-98 (2016).

4. Sawhney, S. et al. Intermediate and Long-term Outcomes of Survivors of Acute Kidney Injury Episodes: A Large Population-Based Cohort Study. American Journal of Kidney Diseases. 69 (1), 18-28 (2017).

5. Saxena, A., Meshram, S.V. Predictors of Mortality in Acute Kidney Injury Patients Admitted to Medicine Intensive Care Unit in a Rural Tertiary Care Hospital. Indian Journalof Critical Care Medicine. 22 (4), 231-237 (2018).

6. Sawhney, S., Fraser, S.D. Epidemiology of AKI: Utilizing Large Databases to Determine the Burden of AKI. Advances in Chronic Kidney Disease. 24 (4), 194-204 (2017).

7. Sales, G.T.M., Foresto, R.D. Drug-induced nephrotoxicity. Revista da Associação Médica Brasileira. 66Suppl 1 (Suppl 1), s82-s90 (2020).

8. Perazella, M.A. Drug use and nephrotoxicity in the intensive care unit. Kidney International. 81 (12), 1172-1178 (2012).

9. Taber, S.S., Mueller, B.A. Drug-associated renal dysfunction. Critical Care Clinics. 22 (2), 357-374 (2006).

10. Pabla, N., Dong, Z. Cisplatin nephrotoxicity: mechanisms and renoprotective strategies. Kidney International. $\mathbf{7 3}$ (9), 994-1007 (2008).

11. Wang, D., Lippard, S.J. Cellular processing of platinum anticancer drugs. Nature Reviews Drug Discovery. 4 (4), 307-320 (2005).

12. Shirmanova, M.V. et al. Chemotherapy with cisplatin: insights into intracellular $\mathrm{pH}$ and metabolic landscape of cancer cells in vitro and in vivo. Scientific Reports. 7 (1), 8911 (2017).

13. Xu, Y. et al. A Role for Tubular Necroptosis in CisplatinInduced AKI. Journal of the American Society of Nephrology. 26 (11), 2647-2658 (2015).

14. Kociba, R.J., Sleight, S.D. Acute toxicologic and pathologic effects of cis-diamminedichloroplatinum (NSC-119875) in the male rat. Cancer Chemotherapy Reports. 55 (1), 1-8 (1971).

15. Perše, M., Večerić-Haler, Ž. Cisplatin-Induced Rodent Model of Kidney Injury: Characteristics and Challenges. BioMed Research International. 2018, 1462802 (2018).

16. Dobyan, D.C., Levi, J., Jacobs, C., Kosek, J., Weiner, M.W. Mechanism of cis-platinum nephrotoxicity: II. Morphologic observations. Journal of Pharmacology and Experimental Therapeutics. 213 (3), 551-556 (1980).

17. Singh, G. A possible cellular mechanism of cisplatininduced nephrotoxicity. Toxicology. 58 (1), 71-80 (1989).

18. Jodrell, D.I. et al. The renal effects of N10-propargyl-5,8dideazafolic acid (CB3717) and a non-nephrotoxic analogue ICI D1694, in mice. British Journal of Cancer. 64 (5), 833-838 (1991).

19. McKeage, M.J. et al. Lack of nephrotoxicity of oral ammine/amine platinum (IV) dicarboxylate complexes in rodents. British Journal of Cancer. 67 (5), 996-1000 (1993).

20. Gautier, J.C. et al. Evaluation of novel biomarkers of nephrotoxicity in two strains of rat treated with Cisplatin. Toxicologic Pathology. 38 (6), 943-956 (2010).

21. Vinken, P. et al. Tissue Kim-1 and urinary clusterin as early indicators of cisplatin-induced acute kidney injury in rats. Toxicologic Pathology. 40 (7), 1049-1062 (2012). 
22. Zorzetto, R., Guimarães, M. Um peixe modelo. Pesquisa FAPESP. 209, 16-21 (2013).

23. Streisinger, G., Walker, C., Dower, N., Knauber, D., Singer, F. Production of clones of homozygous diploid zebra fish (Brachydanio rerio). Nature. 291 (5813), 293-296 (1981).

24. Chakrabarti, S., Streisinger, G., Singer, F., Walker, C. Frequency of gamma-Ray Induced Specific Locus and Recessive Lethal Mutations in Mature Germ Cells of the Zebrafish, BRACHYDANIO RERIO. Genetics. 103 (1), 109-123 (1983).

25. Walker, C., Streisinger, G. Induction of Mutations by gamma-Rays in Pregonial Germ Cells of Zebrafish Embryos. Genetics. 103 (1), 125-136 (1983).

26. Morales, E.E., Wingert, R.A. Zebrafish as a Model of Kidney Disease. Results and Problems in Cell Differentiation. 60, 55-75 (2017).

27. Poureetezadi, S.J, Wingert, R.A. Little fish, big catch: zebrafish as a model for kidney disease. Kidney International. 89 (6), 1204-1210 (2016).

28. McCampbell, K.K., Wingert, R.A. New tides: using zebrafish to study renal regeneration. Translational Research. 163 (2), 109-122 (2014).

29. Drummond, I.A., Davidson, A.J. Zebrafish kidney development. Methods in Cell Biology. 100, 233-260 (2010).

30. Saxén, L., Sariola, H. Early organogenesis of the kidney. Pediatric Nephrology. 1 (3), 385-392 (1987).

31. Diep, C.Q. et al. Identification of adult nephron progenitors capable of kidney regeneration in zebrafish. Nature. 470 (7332), 95-100 (2011).
32. Hill, A.J., Bello, S.M., Prasch, A.L., Peterson, R.E., Heideman, W. Water permeability and TCDD-induced edema in zebrafish early-life stages. Toxicological Sciences. 78 (1), 78-87 (2004).

33. Drummond, I.A. et al. Early development of the zebrafish pronephros and analysis of mutations affecting pronephric function. Development. 125 (23),4655-4667 (1998).

34. Majumdar, A., Drummond, I.A. Podocyte differentiation in the absence of endothelial cells as revealed in the zebrafish avascular mutant, cloche. Developmental Genetics. 24 (3-4), 220-229 (1999).

35. Song, H.D. et al. Hematopoietic gene expression profile in zebrafish kidney marrow. Proceedings of the National Academy of Sciences of the United States of America. 101 (46), 16240-16245 (2004).

36. Gore, A.V., Pillay, L.M., Venero Galanternik, M., Weinstein, B.M. The zebrafish: A fintastic model for hematopoietic development and disease. Wiley Interdisciplinary Reviews: Developmental Biology. 7 (3), e312 (2018).

37. Paik, E.J., Zon, L.I. Hematopoietic development in the zebrafish. The International Journal of Developmental Biology. 54 (6-7), 1127-1137 (2010).

38. Palis, J., Yoder, M.C. Yolk-sac hematopoiesis: the first blood cells of mouse and man. Experimental Hematology. 29 (8), 927-936 (2001).

39. O'Donnell, E.A., Ernst, D.N., Hingorani, R. Multiparameter flow cytometry: advances in high resolution analysis. Immune Network. 13 (2), 43-54 (2013). 
40. Perfetto, S.P., Chattopadhyay, P.K., Roederer, M. Seventeen-colour flow cytometry: unravelling the immune system. Nature Reviews Immunology. 4 (8), 648-655 (2004).

41. Ma, D., Zhang, J., Lin, H.F., Italiano, J., Handin, R.I. The identification and characterization of zebrafish hematopoietic stem cells. Blood. 118 (2), 289-297 (2011).

42. Kulkeaw, K. et al. Purification of zebrafish erythrocytes as a means of identifying a novel regulator of haematopoiesis. British Journal of Haematology. 180 (3), 420-431 (2018).

43. Ratnayake, D., Currie, P.D. Fluorescence-Activated Cell Sorting of Larval Zebrafish Muscle Stem/Progenitor Cells Following Skeletal Muscle Injury. Methods in Molecular Biology. 1889, 245-254 (2019).

44. Kyrylkova, K., Kyryachenko, S., Leid, M., Kioussi, C. Detection of apoptosis by TUNEL assay. Methods in Molecular Biology. 887, 41-47 (2012).

45. Collymore, C., Tolwani, A., Lieggi, C., Rasmussen, S. Efficacy and safety of 5 anesthetics in adult zebrafish (Danio rerio). Journal of the American Association for Laboratory Animal Science. 53 (2), 198-203 (2014).

46. Wilson, J.M., Bunte, R.M., Carty, A.J. Evaluation of rapid cooling and tricaine methanesulfonate (MS222) as methods of euthanasia in zebrafish (Danio rerio). Journal of the American Association for Laboratory Animal Science. 48 (6), 785-789 (2009).

47. Matthews, M., Varga, Z.M. Anesthesia and euthanasia in zebrafish. Institute for Laboratory Animal Research Journal.;53(2):192-204 (2012).
48. Ward, A.C. et al. The zebrafish spi1 promoter drives myeloid-specific expression in stable transgenic fish. Blood. 102 (9), 3238-3240 (2003).

49. Hsu, K. et al. The pu.1 promoter drives myeloid gene expression in zebrafish. Blood. 104 (5), 1291-1297 (2004).

50. Wittamer, V., Bertrand, J.Y., Gutschow, P.W., Traver, D. Characterization of the mononuclear phagocyte system in zebrafish. Blood. 117 (26), 7126-7135 (2011).

51. Hall, C., Flores, M.V., Storm, T., Crosier, K., Crosier, $\mathrm{P}$. The zebrafish lysozyme $\mathrm{C}$ promoter drives myeloid-specific expression in transgenic fish. BMC Developmental Biology. 7, 42 (2007).

52. Mathias, J.R. et al. Resolution of inflammation by retrograde chemotaxis of neutrophils in transgenic zebrafish. Journal of Leukocyte Biology. 80 (6), 1281-1288 (2006).

53. Ellett, F., Pase, L., Hayman, J.W., Andrianopoulos, A., Lieschke, G.J. mpeg1 promoter transgenes direct macrophage-lineage expression in zebrafish. Blood. 117 (4), e49-56 (2011).

54. Harvie, E.A., Green, J.M., Neely, M.N., Huttenlocher, A. Innate immune response to Streptococcus iniae infection in zebrafish larvae. Infection and Immunity. 81 (1), 110-121 (2013).

55. Langenau, D.M. et al. In vivo tracking of $\mathrm{T}$ cell development, ablation, and engraftment in transgenic zebrafish. Proceedings of the National Academy of Sciences of the United States of America. 101 (19), 7369-7374 (2004). 
56. Bajoghli, B. et al. Evolution of genetic networks underlying the emergence of thymopoiesis in vertebrates. Cell. 138 (1), 186-197 (2009).

57. Jessen, J.R., Willett, C.E., Lin, S. Artificial chromosome transgenesis reveals long-distance negative regulation of rag1 in zebrafish. Nature Genetics. 23 (1), 15-16 (1999).

58. Jessen, J.R., Jessen, T.N., Vogel, S.S., Lin, S. Concurrent expression of recombination activating genes 1 and 2 in zebrafish olfactory sensory neurons. Genesis. 29 (4), 156-162 (2001).

59. Liu, X. et al. Zebrafish B Cell Development without a PreB Cell Stage, Revealed by CD79 Fluorescence Reporter Transgenes. Journal of Immunology. 199 (5), 1706-1715 (2017).

60. Bertrand, J.Y., Kim, A.D., Teng, S., Traver, D. CD41+ cmyb+ precursors colonize the zebrafish pronephros by a novel migration route to initiate adult hematopoiesis. Development. 135 (10), 1853-1862 (2008).

61. de Jong, J.L., Zon, L.I. Histocompatibility and hematopoietic transplantation in the zebrafish. Advances in Hematology. 2012, 282318 (2012).

62. Ossowski, P. et al. Differentiation of morphotic elements in human blood using optical coherence tomography and a microfluidic setup. Optics Express. 23 (21), 27724-27738 (2015).

63. McCullough, $\mathrm{K}$. et al. Measuring the population burden of chronic kidney disease: a systematic literature review of the estimated prevalence of impaired kidney function. Nephrology Dialysis Transplantation. 27 (5), 1812-1821 (2012).
64. Drummond, B.E., Wingert, R.A. Insights into kidney stem cell development and regeneration using zebrafish. World Journal of Stem Cells. 8 (2), 22-31 (2016).

65. McCampbell, K.K., Springer, K.N., Wingert, R.A. Atlas of Cellular Dynamics during Zebrafish Adult Kidney Regeneration. Stem Cells International. 2015, 547636 (2015).

66. Wen, X. et al. A zebrafish model of infection-associated acute kidney injury. American Journal of PhysiologyRenal Physiology. 315 (2), F291-F299 (2018).

67. Gong, J., Noel, S., Pluznick, J.L., Hamad, A.R.A., Rabb, H. Gut Microbiota-Kidney Cross-Talk in Acute Kidney Injury. Seminars in Nephrology. 39 (1), 107-116 (2019).

68. Kim, M.J., Moon, D., Jung, S., Lee, J., Kim, J. Cisplatin nephrotoxicity is induced via poly(ADP-ribose) polymerase activation in adult zebrafish and mice. American Journal of Physiology-Regulatory, Integrative and Comparative Physiology. 318 (5), R843-R854 (2020).

69. Parichy, D.M., Elizondo, M.R., Mills, M.G., Gordon, T.N., Engeszer, R.E. Normal table of postembryonic zebrafish development: staging by externally visible anatomy of the living fish. Developmental Dynamics. 238 (12), 2975-3015 (2009).

70. Singleman, C., Holtzman, N.G. Growth and maturation in the zebrafish, Danio rerio: a staging tool for teaching and research. Zebrafish. 11 (4), 396-406 (2014).

71. Wagner, T., Kreft, B., Bohlmann, G., Schwieder, G. Effects of fosfomycin, mesna, and sodium thiosulfate on the toxicity and antitumor activity of cisplatin. Journal of Cancer Research and Clinical Oncology. 114 (5), 497-501 (1988) 
72. Hentschel, D.M. et al. Acute renal failure in zebrafish: a novel system to study a complex disease. American Journal of Physiology-Renal Physiology. 288 (5), F923-9 (2005).

73. Zhou, W., Hildebrandt, F. Inducible podocyte injury and proteinuria in transgenic zebrafish. Journal of the American Society of Nephrology. 23 (6), 1039-1047 (2012).

74. Huang, J. et al. A zebrafish model of conditional targeted podocyte ablation and regeneration. Kidney International. 83 (6), 1193-1200 (2013).

75. Christou-Savina, S., Beales, P.L., Osborn, D.P. Evaluation of zebrafish kidney function using a fluorescent clearance assay. Journal of Visualized Experiments. (96), e52540 (2015).

76. Lieschke, G.J., Oates, A.C., Crowhurst, M.O., Ward, A.C., Layton, J.E. Morphologic and functional characterization of granulocytes and macrophages in embryonic and adult zebrafish. Blood. 98 (10), 3087-3096 (2001).

77. Dasari, S., Tchounwou, P.B. Cisplatin in cancer therapy: molecular mechanisms of action. European Journal of Pharmacology. 740, 364-378 (2014). 